\title{
Correction to: Can search result summaries enhance the web search efficiency and experiences of the visually impaired users?
}

\author{
Aboubakr Aqle $^{1}$ (D) $\cdot$ Dena Al-Thani ${ }^{1}$ (D) $\cdot$ Ali Jaoua ${ }^{2}$ (D)
}

Published online: 2 December 2020

๑) Springer-Verlag GmbH Germany, part of Springer Nature 2020

\section{Correction to: Universal Access in the Information Society https://doi.org/10.1007/s10209-020-00777-w}

In the Original Article, the second author name has published incorrectly as "Dena Al-Tahni". The correct name is "Dena Al-Thani".

The original article has been corrected.

Publisher's Note Springer Nature remains neutral with regard to jurisdictional claims in published maps and institutional affiliations.

The original article can be found online at https://doi.org/10.1007/ s10209-020-00777-w.

Aboubakr Aqle

aaqle@hbku.edu.qa

Dena Al-Thani

dalthani@hbku.edu.qa

Ali Jaoua

jaoua@qu.edu.qa

1 Information and Computing Technology Division, College of Science and Engineering, Hamad Bin Khalifa University, Doha, Qatar

2 Computer Science and Engineering Department, College of Engineering, Qatar University, Doha, Qatar 